\title{
Preliminary Analysis of Grains Bought from Four Markets in Kano State
}

\author{
Uzoma D. Anugwom ${ }^{1}$, Damilola R. Awotunde ${ }^{2}$, Eunice I. Bamishaiye ${ }^{3}$, Auwalu Abubakar ${ }^{4}$ and Toluwaloju \\ O. Adamson ${ }^{5}$
}

${ }^{1}$ Durable Crops Research Department, Nigerian Stored Products Research Institute Kano Station, Kano State, Nigeria

Email: uzomaanugwom [AT\}] yahoo.com

${ }^{2}$ Durable Crops Research Department, Nigerian Stored Products Research Institute Kano Station, Kano State, Nigeria

Email: cnatawal22 [AT] gmail.com

${ }^{3}$ Durable Crops Research Department, Nigerian Stored Products Research Institute Kano Station, Kano State, Nigeria

Email: bamishaiyeeunice [AT] gmail.com

${ }^{4}$ Durable Crops Research Department, Nigerian Stored Products Research Institute Kano Station, Kano State, Nigeria

Email: dawotunde7 [AT] gmail.com

${ }^{5}$ Durable Crops Research Department, Nigerian Stored Products Research Institute Kano Station, Kano State, Nigeria

Email: tee.adamson [AT] gmail.com

\begin{abstract}
The new order in world trade demands strict adherence to the rules of food quality and safety as an essential factor in the selection of raw materials for production since the quality of end products is dependent on that of the raw materials for its production. Therefore, in order to determine the quality of some agricultural grains bought from four markets (Yankaba, Dawanau, Tarauni and A. Rimi) in Kano State, Nigeria. These grains were examined for test weights, pest infestation, level of impurities, and germination potential to determine their export and processing standards. The results showed some difference among the different grains in term of weight, which can be attributed to their difference in physical properties. The result showed that there was some level of impurities present in grains sold in these markets, but no live adult insect was present in all the grain sample. The result also showed that cowpea from respective markets did not meet the standard economic threshold of insect egg free. Cowpea samples had the highest level of insect damage, an average of $2.9 \%$ insect damage was observed. From the result, the average seeds germination in maize and sorghum samples was high (95\% and $88 \%$ respectively) and acceptable according to recommended standards. Determining these terms is important to end users during purchasing, storage, consumption, exportation, and processing, as such will help to increase their knowledge about condition of agricultural produce in our various agricultural market for satisfactory purchasing. There are some food safety standards met by grains sold in these markets, and most commodities sampled too had standards that are either acceptable or unacceptable for consumption, export and processing purpose.
\end{abstract}

Keywords--- grains, standard, impurities, food safety

\section{INTRODUCTION}

The Agriculture sector in Kano contributes more than $70 \%$ of its Gross State Product. Approximately $50 \%$ of the populace is directly or indirectly engaged in some form of agricultural activity. Kano is presently the most irrigated State in Nigeria, with more than 20 dams providing about 2 million cubic metres of water to support agricultural and industrial activities. Current annual production of grains exceeds 4 million metric tons with an estimated value of N721.20b. Cereals (Rice, Wheat and Barley), Legumes (Groundnut and cowpea), Oil Seeds (Soya Beans, Sesame and Castor), Fibers (Cottons and Sisal), Spices (Ginger, Chili Pepper) being the major export crops produced in the State (KANINVEST, 2021).

Much concern has been shown over the fact that Nigeria operates a mono-product economy where virtually all the export earnings come from petroleum products. Petroleum, like most other natural resources is not inexhaustible. Efforts are now on to restore the export of agricultural produce to the pre-petroleum discovery position by the Nigerian government. Therefore, there is need to stimulate the exports of these products by working towards meeting the tastes and 
preferences of not only the local, but also international consumers in our production process (Abdullahi et al., 2018). No efforts should be spared to develop an export culture in our food and agricultural sector. In doing this the government must monitor and provide guideline to assist farmers to comply with the world wide quality practices in food production (FAO, 2021; Dinrifo, 2005). These requirements of quality standards in the food and agricultural production are particularly stringent because of the need to assure consumers' required level of safety. Agro-industrial stakeholders must be abreast of these standards and conventions for safety of consumers and exports of food and agricultural products (Dinrifo, 2005).

Past studies testify that consumers' concerns for healthier lifestyles and environment care are driving forces for reshaping food buying intentions. There is need for adherence to the specification of the various international agro-produce quality standards in order to enhance export of Nigeria's agricultural commodities (FAO, 2021/2018; Marli and Denise, 2006; Dinrifo, 2005). The quality of a commodity depends greatly on the intended use; to illustrate the wide variety of uses of agricultural products, a grain may be used as seeds for planting, used for human nourishment, extraction of raw materials such as oil, starch and starch-derived chemicals for industrial uses. Maize as an example is routinely used as an adhesive to manufacture of papers, and as an excipient or filler for pharmaceuticals. It can be converted into an enormous assortment of industrial chemicals now produced from petroleum sources. For example, new biodegradable plastic products are being made from corn, such as garbage bags, car parts, and packing "peanuts" (Guillermo et al., 2011). There is need for adherence to the specification of the various international agro-produce quality standards in order to enhance export of Nigeria's agricultural commodities (FAO, 2021/2018; Marli and Denise, 2006; Dinrifo, 2005).

Quality analysis are required for the control of finite products in the local markets, so as to increase the certainty that the finite products of a particular food market meet certain standard requirements by reducing the number of nonconformances to the standard (FAO, 2018). It also provides a significant opportunity for continuous improvement of various practices involved for the production and consumption of the finite product, hence, the need to carry out this study.

\subsection{Food quality characteristics}

Test weight is the weight of clean grain which is reported in pounds/bushel (Ib/bu) or in kilograms $(\mathrm{kg} 0$. It is mostly affected by kernel density and packing properties, which is influenced by kernel characteristics such as shape, uniformity, size, moisture content and surface (Tilley and Miller, 2012). Grain millers often use test weight (TW)as a predictor of flour yield where higher test weight indicates a higher flour yield. TW is an important quality index in the USA wheat industry as it is used in grade determination, which ultimately determines the price of the commodity (Tilley and Miller, 2012).

Seed quality describes the potential performance of a seed lot. Trueness to variety; the presence of inert/foreign matter, seed of other crops, or weed seed; germination percentage; vigor; appearance; and freedom from disease are important aspects of seed quality (AHDB, 2016). High-quality seed lots should meet minimum standards for each of these characteristics (AHDB, 2016; Ferguson et al, 1991). According to FAO (2018), abnormal seedlings lack a shoot, root or have other malformations.

Inert/foreign matter indicates the percentage of extraneous material such as dirt, stems, leaves, and other seeds in a seed lot (AHDB, 2016). Foreign matter is an inconvenience to grain handlers and millers because it generates more dust during handling and requires more extensive cleaning than dockage-free shipments (James and Maria, 2012). Many of the components of foreign matter can affect the appearance and in particular, may increase the number of visible specks in finished products. Presence of inert matter reduces the value of seed because it is best to choose seed with less percent level of inert matter (FAO, 2021/2018; Ferguson et al, 1991).

Pest infestation information is important in agro-marketing, which is why exclusion is a good management strategy (FAO, 2021/2018). Inspection of agro-produce bought from local markets for pest infestations is imperative in order to best inform the farmers and as well assure the end-users. Regular monitoring can answer several important questions such as; what type of pests are present, are the numbers great enough to warrant rejections by users, is the pest population safe for storage purchases? And so on.

This information can help end users during purchasing, storage, consumption, exportation, processing of agricultural produce from our local markets, which is relative to the selection of suitable markets to buy produce for sustainability (Abdullahi et al., 2018; James and Maria, 2012). This write-up therefore presents basic facts about the standard weight, level of impurity, level of insect infestations and germination potentials of selected grains bought from selected markets in Kano State Nigeria. 


\subsection{Justification}

In today's competitive marketplace, quality has become a distinctive and vital aspect for all types of products especially for agricultural food (agri-food) products. Produce quality plays an important role in the marketing of agricultural commodities which is needed to improve the livelihood of farmers and grain handlers in Kano State, and as well increase food security. Characteristics such as standard weight, germination potential, purity, vigor, and appearance are important to processors and end users, which means that achieving and maintaining high agricultural product quality is the goal of every stakeholder. Therefore discovering quality standards in the agricultural industry is of paramount importance.

\subsection{Objective}

To conduct a preliminary study on agricultural grains bought from four markets in Kano.

To determine the level of quality standard of agricultural grains obtainable in Kano markets.

\section{METHODOLOGY}

The study samples were bought from four popular markets, located in four different local government areas (L.G.A.); Tarauni market (Tarauni L.G.A.), Abubakar Rimi market (fagge L.G.A.), Dawanau international grain market (Dawakin Toffa L.G.A.) and Yankaba markets (Nassarawa L.G.A.) Kano State respectively.

Grains selected for study were maize (Zea mays), groundnut (Arachis hypogeae), Bambara nut (Vigna subterranea), cowpea (Vigna unguiculata), pearl millet (Pennisetum glaucum) and sorghum (Sorghum bicolor). Each grain sample (100 g) was bought from 6 different sellers in respective markets, and samples from respective markets were massed for preliminary analysis.

The following terms were examined and each experiment was repeated three times (x 3);

Test weight of samples was determined by taking the weight of 20 seeds randomly selected from respective markets grain lot using a weighing balance. Each treatment was repeated three times and the average taken to be the standard weight for respective grain lot (FAO, 2021/2018).

Level of impurity of samples was determined by taking 200 grams from respective seed lot and carefully sorting out impurities i.e. matters that are unwanted in the produce such as plant mater, sand particles, dead insect, insect damaged seeds etc. and percentage level determined using the formula below:

$\frac{\text { weight of foreign mater }}{200 \mathrm{~g}} \mathrm{X} \frac{100}{1} \quad$ was the percentage level of impurity for respective sample (FAO, 2021/2018; AHDB, 2016).

Insect infestation level was determined by first shaking respectively massed grains vigorously to miss-up properly before taking out $200 \mathrm{~g}$ from the lot, taken to represent a market sample, each weighed sample were carefully inspected for live adult insects, number of seeds with emergence holes/seeds with damages caused by insects and number of seeds with insect egg, all counted and recorded (FAO, 2021/2018; AHDB, 2016).

Insect damage levels were examined by picking two hundred seeds randomly from each grain lot of $200 \mathrm{~g}$, respective grain lot of 200 seeds were carefully inspected using the microscope for holes caused by insect emergence or feeding activities;

$\frac{\text { number of insect damaged seeds }}{\text { total number of grains inspected (200) }} \times \frac{100}{1}$ was the percentage of insect damage for respective markets (FAO, 2021/2018; AHDB, 2016).

Egg counts was determined by picking two hundred seeds (200) randomly from respective seed lots of $200 \mathrm{~g}$, each grain lot (200 seeds) was carefully inspected using the microscope for presence of insect egg;

$\frac{\text { number of seeds with eggs }}{\text { total number of seeds inspected (200) }} \times \frac{100}{1}$ was the percentage number of eggs present in samples.

Germination potential was determined by randomly picking 200 seeds from respective sample and using the water method to test for their germinability,

$\frac{\text { number of normal seeds }}{\text { number of seeds set for germination (20) }} \times \frac{100}{1} \quad$ was the percentage germination (FAO, 2018). 


\subsection{Test/standard weight of samples}

\section{RESULTS AND DISCUSSIONS}

The results (chat) showed that there were difference among the different grains in term of weight and this can be attributed to their difference in physical properties with Bambara-nut having the highest average weight of $9.7 \mathrm{~g}$, it was followed by groundnut $(8.2 \mathrm{~g})$, maize $(5.5 \mathrm{~g})$, cowpea $(4.7 \mathrm{~g})$, sorghum $(3.5 \mathrm{~g})$ and pearl millet which weighed $1.4 \mathrm{~g}$. On the other hand, samples were similar in weight when compared according to markets which indicates the trueness of varieties.

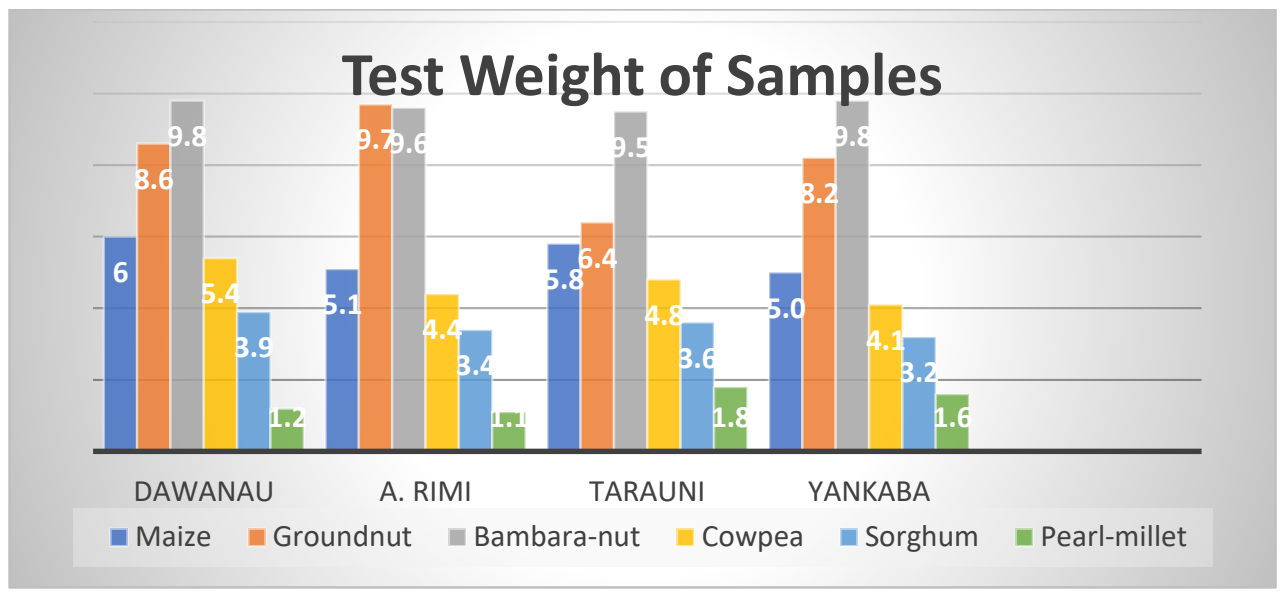

Figure 1: Test weight of samples.

\subsection{Level of impurities in grains}

The result (chat) showed that there are impurities at some level present in grains sold in these markets, the groundnut sample from Tarauni market $(8.8 \%)$ had the highest level of impurities which was not in line with the acceptable standard of $2 \%$ level by Ferguson et al. (1991). All other grain samples had between 1.7 and $0.1 \%$ impurity which is an acceptable level for impurities in grain as recommended by Ferguson et al. (1991). On the other hand, the average level of impurity in all the grain sampled was $1.0 \%$ which was not up to the prescribed standard of $0.5 \%$ foreign material export grading standard for Canadian Western Amber Durum (CWAD) wheat milling grade (James et al., 2012). This means that there is need for improvement in postharvest grain handling in Kano State so as to reduce the percentage level of impurity to levels acceptable around the globe.

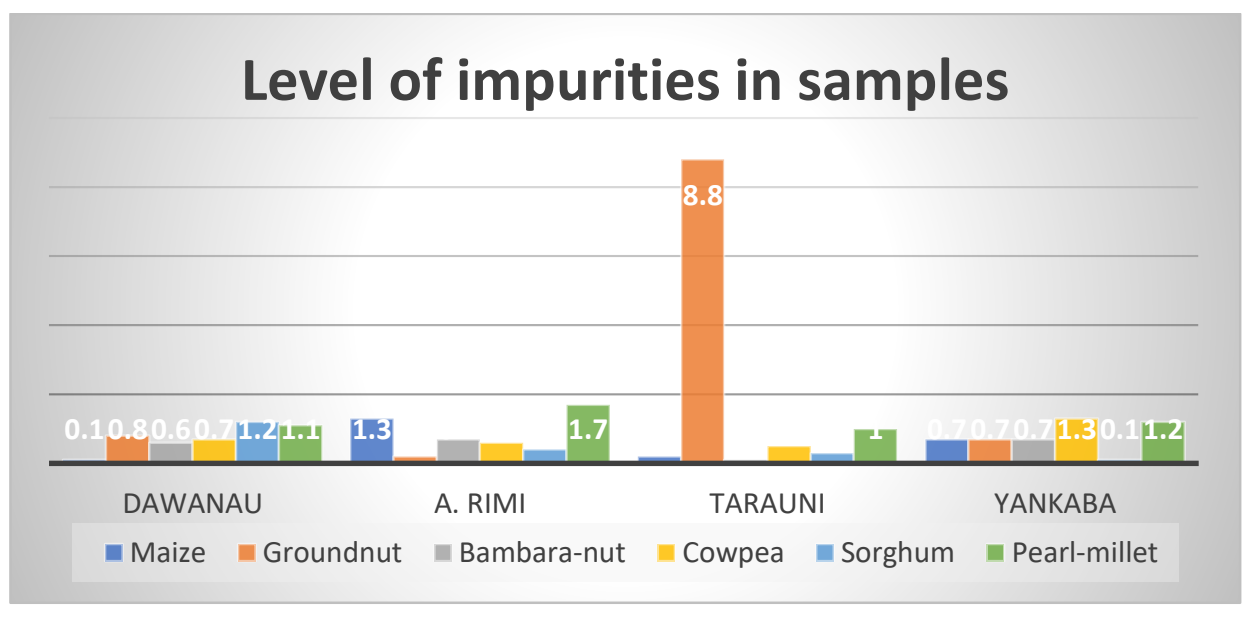

Figure 2: Percentage level of impurity in samples.

\subsection{Insect count}

The result (chat) showed that no live adult insect was present in all the grain samples, which according to Abdullahi et al. (2018) qualifies the produce for export in terms of insect free by the Malasian Cocoa Board economic threshold of insect free produce. 


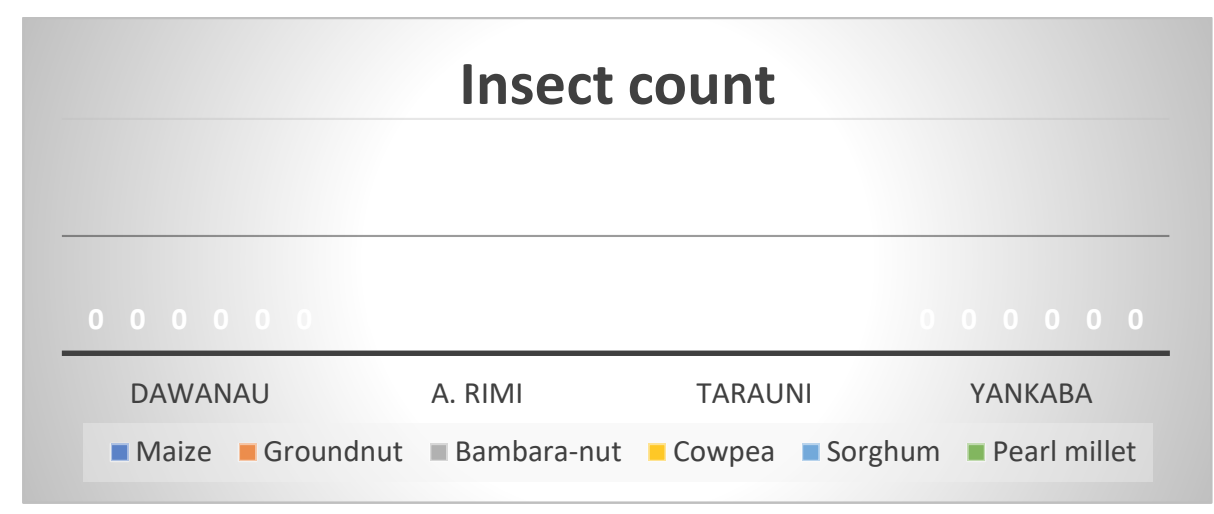

Figure 3: number of live adult insects' present in samples.

\subsection{Insect egg count}

From the result, insect egg was seen in cowpea and maize samples only. Yankaba market had the highest egg count in cowpea $(40 \%)$, it was followed by cowpea sample bought from Tarauni market (25\%), and lastly cowpea from Abubakar Rimi market (5\%), but no egg (0\% egg) was found in cowpea sample from Dawanau International Grain Market. While on the other hand maize from Dawanau was the only maize sample that had presence of insect egg at $1 \%$, other maize samples had no insect egg contamination. This result showed that cowpea sold in Kano markets did not meet the standard economic threshold of insect egg free, and $<2.5 \%$ insect damage set by the Malasian Cocoa Board (Abdullahi et al., 2018). Other grain sampled can be termed free of insect eggs and met the standards set by the Malasian Cocoa Board (Abdullahi et al., 2018).

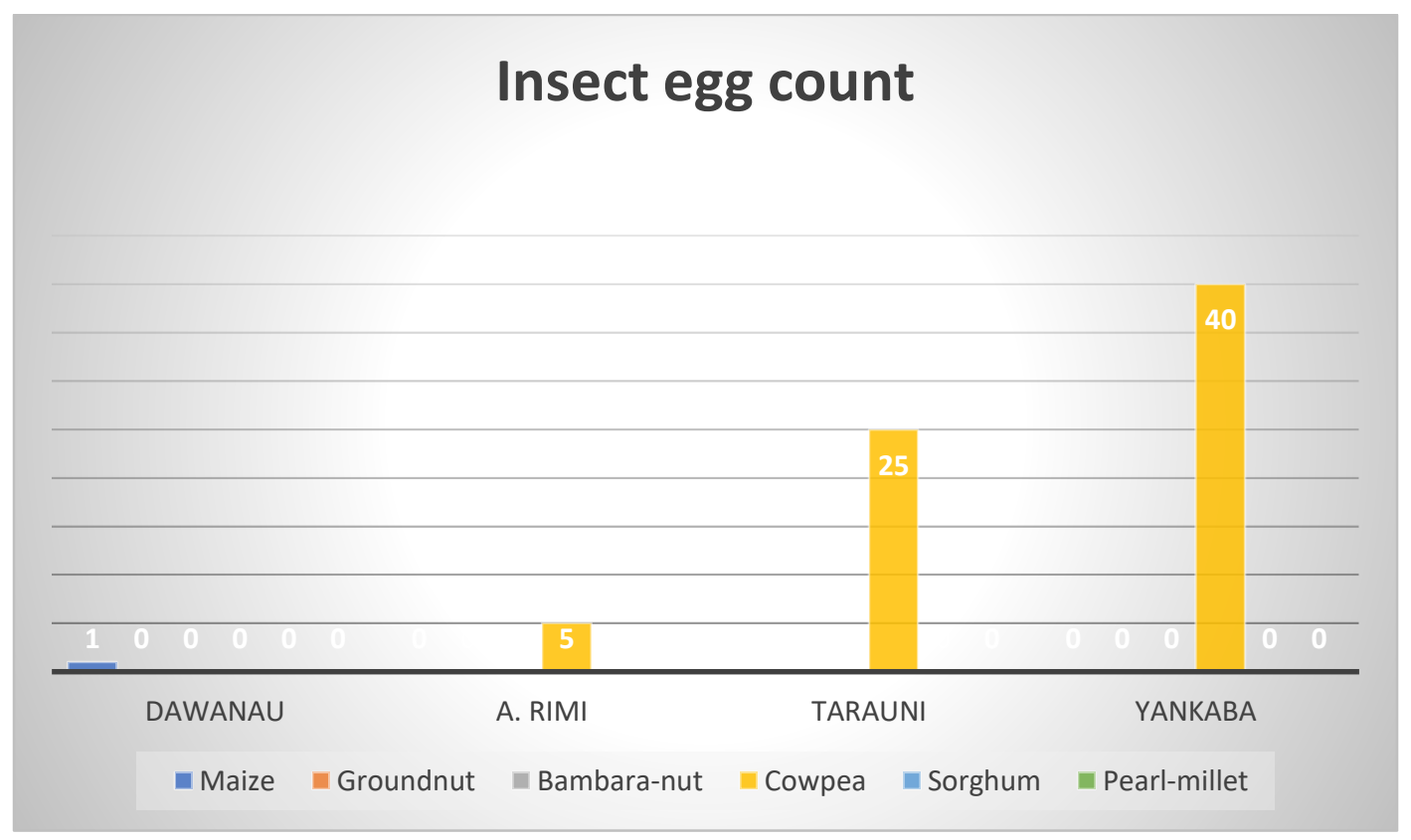

Figure 4: presence of insect egg.

\subsection{Level of insect Damage}

The result showed that cowpea from Yankaba market $(7.5 \%)$ had the highest emergence hole, it was followed by cowpea from Tarauni market (3\%), Abubakar Rimi market (1\%), while no insect emergence hole or damage to seed was observed in cowpea sample from Dawanau market $(0 \%)$.

No insect damage was observed in Bambara-nut samples bought from Dawanau, while $2 \%$ insect damage was observed in Bambara-nut samples from A. Rimi, Tarauni, and Yankaba markets respectively.

Maize bought from Dawanau had $1.5 \%$ insect damage, and also maize bought from Tarauni had $0.5 \%$ insect damage, while samples bought from Abubakar Rimi and Yanakaba markets had no insect damage. 
Also in the result (chat 5) groundnut bought from A. Rimi had $0.5 \%$ insect damage, while groundnut sample from A. Rimi, Tarauni and Yankaba markets had $0 \%$ insect damage. From the result, an average of $2.9 \%$ insect damage was observed in the cowpea sold in the selected markets and it also means that cowpea from these markets did not meet the acceptable standard in terms of insect damage; $<2.5 \%$ insect damage set by the Malasian Cocoa Board (Abdullahi et al., 2018). Other produce (Ground-nut, Bambara-nut, Maize, Sorghum and Pearl-millet) had insect damage at acceptable levels.

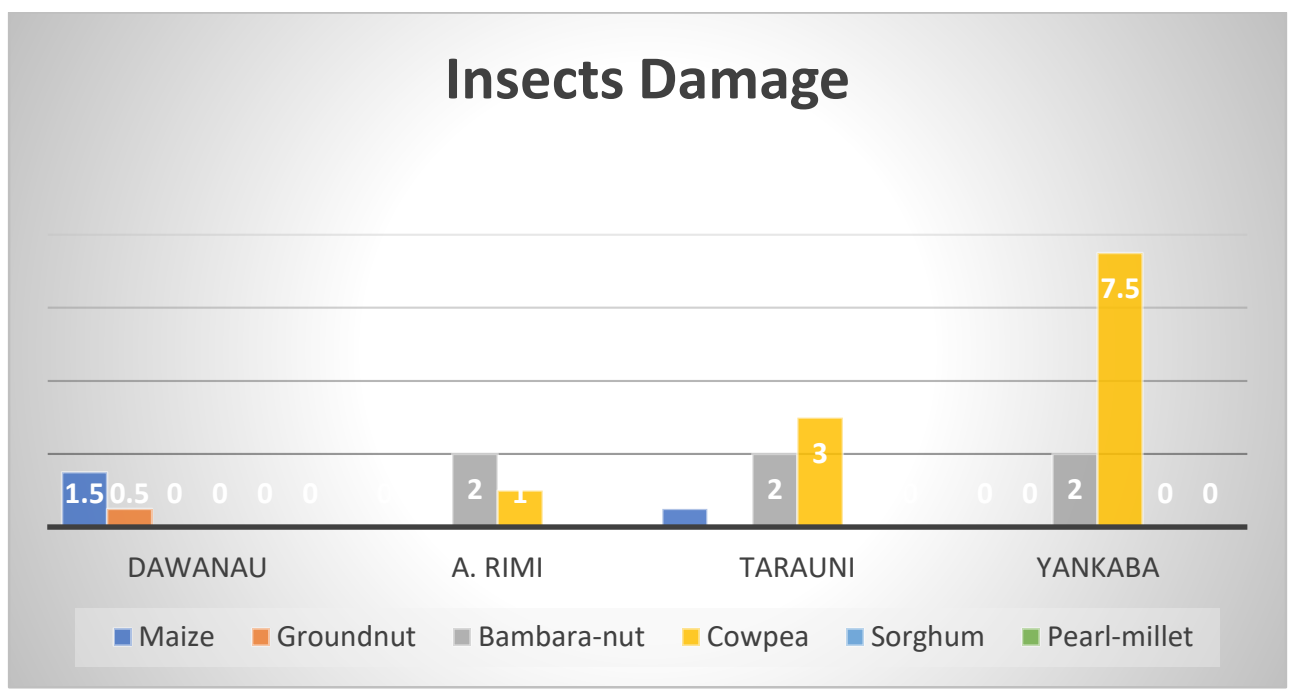

Figure 5: level of insect imergence hole (damage) in samples.

\subsection{Germination potential}

The result showed that maize from respective markets have the highest level of germination potential of $95 \%$, it was followed by sorghum which had an average of $88 \%$ germination. Pearl-millet had an average of $78 \%$ germination, while groundnut had $68 \%$ germination, bambara-nut had $57 \%$ and cowpea was observed to be the samples with the least (35\%) level of average germination in this research. From the result, the average seeds germination in maize and sorghum samples was high (95\% and $88 \%$ respectively) and acceptable according to recommendations by FAO (2018; 2021) and Ferguson et al. (1991). Pearl-millet (78\%), groundnut (68\%), bambara-nut (57\%), and cowpea (35\%) samples were below the recommended level for procurements (FAO, 2018). According to FAO (2021); Ferguson et al. (1991), grains for export should be at least $80 \%$ germinable, and this low level of germinations can be attributed to species selected for this research.

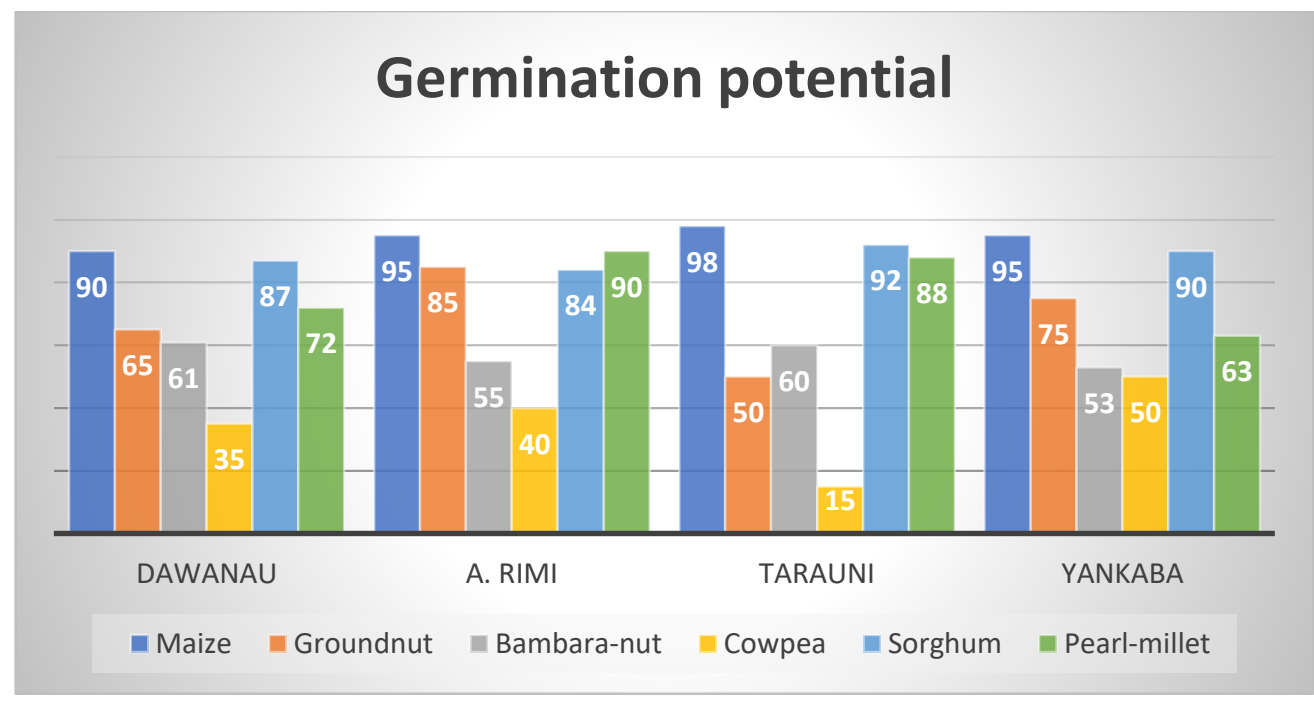

Figure 6: germination potential of respective crops. 


\section{CONCLUSIONS}

Based on the result obtained from the study, the following conclusions were made:

1. Samples were similar in test weight when compared according to markets which indicates the trueness of selected species in the markets.

2. There is some food safety level for grain commodities not met by grains sold in these markets, but most commodities sampled had standards that are acceptable for consumption, export and processing purpose.

\subsection{Recommendations}

From studies carried out in this work, recommendations are that:

1. It is advisable to further researches into means for reducing impurities in our agricultural produce.

2. There is need for more research in the management of cowpea weevil infesting cowpea in postharvest.

\section{REFERENCES}

1) Abdulahi G., Muhamad R., Dzolkhifli O., and Sinniah U.R. Damage Potential of Tribolium castaneum (Herbst) (Coleoptera: Tenebroinidae) on Cocoa Beans: effect of initial adult population density and post infestation storage time. Journal of Stored Products Research, 75:1 - 9, 2018.

2) Agriculture and Horticulture Development Board (AHDB). Inspecting Grains for Defects and impurities. AHDB Cereals and Oilseeds. Available online: cereals.ahdb.org.uk, 2016.

3) Dinrifo Rufus Rotimi. Quality, Production and Export of Agricultural and Food Commodities in Nigeria. International Conference on Science and Technology, FUT, Akure, Nigeria. 14-19 August, 2005. Retrieved online at: https://www.researchgate.net/publication/284183925, 2005.

4) Ferguson J.M., Keys R.D., McLaughlin F.W., and Warren J.M. Seed and Seed quality. NC State Extension Publication, 1991. Retrieved online; 25-08-2021.

5) Food and Agricultural Organisation of the United Nation (FAO). Seed Toolkit; module 3: seed quality assurance. ISBN 978-92-5-130951-3, 2018.

6) Food and Agricultural Organisation of the United Nation (FAO). Seed and Seed Quality: Technical Information for FAO Emergency Staff. FAO Seed and Plant Genetic Resources Service Rome, Italy. AGPS Draft Publication, 2021. Retrieve online: 28-04-2021.

7) Guillermo P. Moreda, Margarita Ruiz-Altisent. Quality of agricultural products in relation to physical conditions. Encyclopedia of Agrophysics; Springer. Glinski. J.: Horabik. J.: Lipiec, J.: (Eds.). Online; http:// www. Springer.com/978-90-481-3584-4, 2011.

8) James E. Dexter, and Maria Grazia D'Egidio. Grading Factors Impacting Durum Wheat Processing Quality. Durum Wheat (second edition); Chemistry and Technology. American Association of Cereal Chemists International. Pp 235-250, 2012.

9) KANINVEST. Kano State; Investment Potentials. Kano Sate Ministry of Science, Technology and Innovation, 2021. Retrieved online @ Investment Potentials | Kano (kanostate.gov.ng) on 26-08-2021.

10) Marli A. Ranal and Denise Garcia De Santana. How and Why to Measure the Germination Process. Revista Brasil. Bot., V.29, n. 1, Pp 1 - 11, 2006.

11) Tilley M. and Miller R.A.. Wheat Breeding and Quality Evaluation in the USA. Breadmaking (Second Edition). Improving Quality. ScienceDirect; Woodhead Publishing Series in Food Science, Technology and Nutrition; Pp 216 - 236, 2012. 